\title{
Roundtable on Sustainable Palm Oil - RSPO. The second RSPO meeting in Jakarta in October 2004
}

\author{
Hubert OMONT \\ CIRAD Tree Crops Department, TA 80 / PS3, \\ 34398 Montpellier Cedex 5, France \\ <hubert.omont@cirad.fr>
}

\begin{abstract}
In a context of discord between producers and environmental conservationists, RSPO is an initiative by stakeholders in the "Oil Palm" commodity chain to promote sustainable palm oil production. RSPO, using a multiple-stakeholder process, based its approach on drawing up a set of credible criteria that define the sustainability of palm oil production and which are acceptable to the different categories of stakeholders. The purpose of the second meeting (RT2) was to: i) propose a platform for exchanging views and experience between stakeholders from industrialized and emergent countries, to seek a clear definition of the "sustainable palm oil" concept; ii) identify practical projects for facilitating the implementation of good practices and for proceeding with their introduction; and: iii) strengthen cooperation and mutual assistance between stakeholders and international agencies to promote the production and use of "sustainable palm oil".
\end{abstract}

Key words: palm oil, sustainability, stakeholders, roundtable, good practices, criteria

riment of forests and without any particular precautions. As a result, the entire commodity chain has come in for sometimes fierce criticism and attacks from environmental conservationists. The aim in setting up a Roundtable on Sustainable Palm Oil was to take these criticisms into account and attempt, together, to find answers that would satisfy all stakeholders in the commodity chain, and environmental conservationists.

\section{The RSPO initiative}

RSPO is an initiative by stakeholders in the "Oil Palm" commodity chain to promote sustainable palm oil production, in a context of discord between producers and environmental conservationists. This approach resulted from discussions between WWF, Aarhus, Golden Hope, MPOA, Migros, Sainsbury and Unilever in 2002, to take up the major challenges facing the commodity chain:

- according to the President of RSPO, production needs to be virtually doubled by 2030 to meet the demand for oil [1], i.e. notably by increasing productivity and/or the areas planted, which is not without its environmental consequences.

- according to WWF (Forest Conversion Initiative), oil palm and soybean are the two crops that most threaten the existence of tropical forests [2]. Moreover, some NGOs have launched virulent attacks against oil palm growing on Internet sites or through advertisements in the press.

This second Roundtable meeting followed on from the first RSPO "inaugural" meeting in Kuala Lumpur in August 2003. Several categories of stakeholders expressed their wish during the PIPOC meetings to see an initiative designed to improve the sustainability of palm oil production by signing a Statement of Intent. RSPO came legally into existence in April 2004 with its official registration in Zurich, as an association under article 60 of the Swiss Civil Code. An interim Executive Board was nominated to manage organization up to the first general assembly meeting. RSPO has a secretariat in Kuala Lumpur and much information on the statutes and bylaws, activities, members, etc. is available on the website: http://www.sustainable-palmoil.org/.

\section{Aims}

The aims of RSPO, as stated in the statutes, are as follows:

"RSPO is an association created by organisations carrying out their activities in and around the entire supply chain for palm oil to promote the growth and use of sustainable palm oil through co-operation within the supply chain and open dialogue with its stakeholders".

In particular, the RSPO will work on the following tasks:

a. research and development of definitions and criteria for the sustainable production and use of palm oil;

b. undertake practical projects designed to facilitate implementation of sustainable best practices;

c. development of solutions to practical problems related to the adoption and verification of best practices for plantation establishment and management, procurement, trade and logistics; d. acquisition of financial resources from private and public funds to finance projects under the auspices of the Roundtable on Sustainable Palm Oil;

e. communication of the Roundtable's work to all stakeholders and to a broader public." 


\section{Members}

There are two types of members, ordinary members acknowledged to be directly involved in the supply chain, and affiliate members. The ordinary members ${ }^{1}$ are divided into 7 categories: oil palm growers (23 members), palm oil processors and traders (13 members), consumer goods manufacturers (7 members), retailers (3 members), environmental/nature conservation NGOs (5 members), social/development NGOs (2 members), banks/investors (2 members). There are 19 affiliate members (including 2 private individuals).

The Executive Board ${ }^{2}$ has 16 members, 4 for the growers category and 2 for each of the other categories. One seat is reserved for smallholders, but it is not filled at the moment for lack of representation of that group among the ordinary members. Unilever holds the presidency of the Board, assisted by WWF (Switzerland), GAPKI (Indonesia), MPOA (Malaysia) and FEDEPALMA (Colombia) as vicepresidents.

The affiliate members are mostly input suppliers and 2 research organizations, CIRAD and Wageningen. Research is welcome in the debate, but it is not accorded a major role at this stage in constructing the initiative: a tangible result needs to be achieved rapidly, whilst the implication of scientific research in sustainable development may not yet be clearly obvious for those involved in RSPO.

\section{The approach}

RSPO has decided to base its approach on drawing up a set of credible criteria that define the sustainability of palm oil production, and which are acceptable to the different categories of stakeholders in the supply chain; to do this, using a multiple-stakeholder process has been proposed.

To develop these criteria, the Executive Board is relying on an outside consultant, ProForest, a restricted RSPO working group, plenary meetings (RT2), and public consultations. A regularly updated website carries all the information and serves as a focal point for all the work and consultations of the stakeholders. A newsletter is circulated regularly to all members.

ProForest has established a procedure for constructing the set of criteria, has prepared a working document [3] to serve as a starting point for the working group, and will be coordinating the group's activities.

\section{The Criteria Working Group (CWG)}

The Executive Board selected 25 of the 70 members nominated by their organizations to form the working group. Those 25 people $^{3}$ are divided into 4 categories: i) producers, ii) trade, industry and investors, iii) environmental concerns, iv) social.

The members of the group are required to liaise with the other people in their category. CIRAD has a representative in the working group and has set up a reference group of 6 people to assist him in his task.

$\overline{{ }^{3} \text { See box } 2 \text {. }}$

\footnotetext{
${ }^{1}$ Figures at the end of February 2005

2 See box 1 .
}

\begin{tabular}{|lll|}
\hline \multicolumn{1}{|c|}{} & \multicolumn{1}{c|}{ Box 1 } \\
President & \multicolumn{1}{c|}{ RSPO Executive Board } & \\
Vice-President & Jan Kees Vis & Unilever \\
Vice-President II & Matthias Diemer & WWF Switzerland \\
Vice-President III & Derom Bangun & Indonesian Palm Oil Producers \\
Vice-President IV & MR Chandran & Association (GAPKI) \\
& Jens Mesa-Dishington & Malaysian Palm Oil Association \\
& & FEDEPALMA - National Federation \\
Treasurer & & of Oil Palm \\
Members & Fausta Borsani & Growers of Colombia \\
& & Federation of Migros \\
& lan Mclntosh & Cooperatives \\
& Bachtiar Karim & Aarhus United \\
& Tony Lass & PT Musim Mas \\
& Rikke Netterstrom & Cadbury Schweppes Plc \\
& Dian Kosasih & The Body Shop \\
& Lea Borkenhagen & WWF-Indonesia \\
& Rudy Lumuru & Oxfam GB \\
& & Watch \\
\hline
\end{tabular}

The CWG has an 18-month mandate to produce:

- a set of criteria defining sustainable palm oil production,

- directives enabling a national interpretation of the criteria,

- rules for using the criteria and settling disputes.

The group gives its opinion on the successive versions of these 3 documents, and group members consult the categories of stakeholders they represent on these different versions. In addition, at least two public consultations are scheduled, during which everyone will have an opportunity to express views on the proposals being drawn up.

The CWG works as far as possible by consensus; failing that, a vote has to achieve a majority of $2 / 3$ in each group - no decision can be taken against the opinion of one of the groups.

These criteria are being drawn up with the help of numerous documents of good palm oil production practices, the ISO 59 Guide (standardization code of good practice), and the ISEAL code (code of good practice for establishing social and environmental standards).

In the working document drafted by ProForest, 5 components cover 36 criteria: legislation: 2 criteria; technical: 10 criteria; environment: 7 criteria; social: 9 criteria; plantation establishment: 8 criteria.

The first CWG meeting was held on Monday 4 October 2004, to discuss its internal functioning and express an initial view on the working document, prior to meetings scheduled for the second plenary meeting of RSPO to discuss the criteria.

The following points are worth noting among the comments in the minutes:

- queries on the representativeness of the members (no smallholders, not enough representatives from Africa, etc.).

- the proposal that research should play a greater role in developing the criteria (but only selecting researchers or organizations as technical advisors on request).

\section{The second plenary meeting of RSPO}

After the first meeting (RT1) in August 2003, RSPO was confirmed in its previously mentioned objectives.

The purpose of the second meeting (RT2) was to:

- Propose a platform for exchanging views and experience between stakeholders from industrialized and emergent countries, to seek a clear definition of the "sustainable palm oil" concept;

- Identify practical projects for facilitating the implementation of good practices and for proceeding with their introduction; 


\begin{tabular}{|c|c|}
\hline \multicolumn{2}{|c|}{$\begin{array}{c}\text { Box } 2 \\
\text { Criteria Working Group }\end{array}$} \\
\hline Name & Organization \\
\hline \multicolumn{2}{|l|}{ Producers } \\
\hline Simon Lord & NBPOL \\
\hline Jean-Charles Jacquemard & CIRAD/SOCFINDO \\
\hline Bernard Tinkler & Consultant \\
\hline Mohd Ramli Adnan & FELDA \\
\hline Asril Darussamin & IPOC \\
\hline Marcello Brito & Grupo Agropalma \\
\hline Kee Khan Kiang & Applied Agricultural Research \\
\hline Thomas Fairhurst & PRPOL \\
\hline Joseph Tek IJM & MPOA \\
\hline \multicolumn{2}{|l|}{ Supply Chain and Investors } \\
\hline lan McIntosh, & Aarhus United UK \\
\hline Tim Stephenson (Alternate for lan Mclntosh) & Aarhus United UK \\
\hline Bachtiar Karim & PT Musim Mas \\
\hline Manuel Davila & Daabon Group \\
\hline Jan van Driel & GHPB \\
\hline Doris Nichol & PORAM \\
\hline \multicolumn{2}{|l|}{ Environmental } \\
\hline Fitrian Ardiansyah & WWF Indonesia \\
\hline Gan Lian Tiaong & KLK \\
\hline John Payne & WWF Malaysia \\
\hline \multicolumn{2}{|l|}{ Social } \\
\hline Rudy Lumuru & Sawit Watch \\
\hline Marcus Colchester & Sawit Watch \\
\hline Lea Borkenhagen & OXFAM Indonesia \\
\hline
\end{tabular}

- Strengthen cooperation and mutual assistance between stakeholders and international agencies to promote the production and use of "sustainable palm oil".

Over 300 people attended the second plenary RSPO meeting on 5 and 6 October 2004. The full programme and minutes of sessions are available on the previously mentioned website. After an opening session addressed by the Indonesian Minister of Agriculture, the first plenary session comprised 2 presentations:

- a statement by RSPO on developments since the Kuala Lumpur meeting, by Jan K. Vis, President of the RSPO interim Executive Board; - presentation of the working document Framework for Drafting Criteria for Sustainable Palm Oil, by Ruth Nussbaum, ProForest.

This presentation served to prepare for the second working group session.

During the second session, the participants first broke up into 5 groups to discuss the criteria working document:

- Legal \& Technical component;

- Environmental component;

- Social component;

- Plantation establishment component;

- Supply chain component.

They then discussed their work in a plenary session. The list of draft criteria and session minutes can also be found on the website.
Everyone agreed that the CWG still has much to do to acquire feedback from all the stakeholders involved.

During the third plenary session, the progress made in ongoing activities by certain Roundtable members was presented: IPOC/WWF Indonesia, MPOA, WWF Switzerland, Sawitwatch, IFC, Friends of the Earth.

During the fourth session, the participants divided up unto 4 working groups to discuss projects arising from the call for proposals issued by RSPO in August:

- Best Management Practices - Plantations;

- Best Management Practices - Smallholders;

- Plantation Development;

- Supply Chain.

Thirteen projects were submitted for discussion during the meeting. All the projects were considered in phase with the sustainability objectives and were therefore endorsed by RSPO, but projects of a general scope seemed to be a greater priority than those raising the issue of indicators; funding, or the search for funding, remained the responsibility of those submitting the projects. These discussions provided an opportunity for project proposers to meet potential partners and sponsors.

During the closing session, stock was taken of the two days and RSPO's prospects were set out.

The RSPO Organizing Committee and Secretariat considered that the targets set for this RT2 meeting had been reached:

- it provided stakeholders in the supply chain, from industrialized and emergent countries, and their partners, with a platform for an exchange of views and experiences, to clarify concepts and work on defining sustainable palm oil production;

- it enabled projects to be put forward and discussed which facilitate the implementation of good practices in the palm oil supply chain; - it strengthened cooperation between stakeholders, and support to those stakeholders, for promoting sustainable palm oil production and use.

All those wishing to do so were able to express their point of view, either during plenary sessions (WWF, Sawitwatch, MPOA and IPOC), or, for absentees, in a document circulated during the sessions (Friends of the Earth, EWNI).

The process for establishing sustainability criteria was presented - the Consultant, Proforest, working group, consultation methods - and the participants were invited to give their views on these different points and on the working version of the criteria document:

- they accepted the process and operating method recommended for the restricted working group;

- they accepted the proposed timeframe;

- they discussed the first criteria proposed; 
- several categories of stakeholders agreed on an internal consultation procedure.

Numerous participants pointed out that the current approach was highly geared towards large plantations and paid little attention to problems specific to smallholders. They asked for reassurances that the concerns and constraints of smallholders would be taken into account when drawing up the criteria. Indeed, their role is not restricted to palm oil production, but they often constitute the social fabric in poor, rural production zones, with a strong potential impact on the environment. In addition, the establishment of new plantations emerged in a major way during this roundtable (notably with regard to social impacts and biodiversity). This is relatively new for a commodity chain that has focused up to now more on its efforts to achieve sustainable development of existing plantations. Lastly, little technical consideration was given to implications in terms of costs or access to the market.

\section{Prospects}

RSPO reiterated the importance of the challenges facing the palm oil supply chain and wishes to proceed rapidly: with the expected doubling of demand for palm oil by 2030, a balance needs to be found quickly that will make it possible to satisfy food demand whilst conserving forest ecosystems and biodiversity, combined with responsible/socially acceptable behaviour in respect of local communities.
For the time being, priority is given to establishing credible sustainability criteria that are acceptable to all stakeholders; the CWG is to present its conclusions on the criteria and the procedures for their implementation in November 2005. Initiatives have already been taken that ought to be developed and consolidated, and each category of stakeholders needs to move the process forward in accordance with its own specificities: it is not a matter of reaching perfection immediately, but of committing oneself to adopt principles and to use the criteria to assess performance.

As regards research, its participation in the process is welcome, but it has not been accorded an active role in the short term, and its possible contribution is probably not clearly perceived.

This RSPO initiative is not an isolated process, but fits in with a set of wider initiatives to which numerous commodity chains subscribe today (SAI, Eurepgap, FSC, etc.). Through new mechanisms that are changing the governance of commodity chains and markets in industrialized and emergent countries, it is in this respect a privileged case for analysing what is tending to foreshadow an evolution in a majority of agricultural sectors that is affecting developing countries.

Numerous questions arose during the discussions, and many others can already be foreseen to which answers will have to be found in order to establish sustainable palm oil production. Research therefore rapidly needs to become an active partner in the process and CIRAD, which is committed to this issue, can help to highlight links between the environment, biodiversity, stakeholders and agriculture. CIRAD can assert its technical skills for becoming a partner in some of the endorsed projects. It can also build alliances and new partnerships to advance the initiative by proposing new projects. Contributions will be particularly developed in two fields: development of indicators and the contribution of stakeholders to sustainable palm oil production.

Lastly, much has been said, but a considerable amount remains to be done to convert words into action; the elected Executive Board is getting to grips with keeping the current dynamics going (work of the CWG and public consultations) and with preparing for RSPO RT3. ()

\section{REFERENCES}

1. VIS JK. Opening Speech by the President of RSPO, Roundtable Conference on Sustainable Palm Oil, October 5-6 2004, Jakarta, Indonesia.

2. WWF. Oil palm and Soy: The Expanding Threat to Forests. Forest Conversion Initiative fact sheet, 1996.

3. JENNINGS S, NUSSBAUMM R. Framework for Drafting Criteria for Sustainable Palm Oil: a discussion paper to begin the process of developing criteria for the Roundtable on Sustainable Oil Palm. Proforest 2004; [31 p]. 